COMENTARIO:

\title{
ACTUALIDAD Y POTENCIAL \\ DE LA ARQUEOLOGÍA INTERNODAL SURANDINA
}

\author{
ACTUALITY AND POTENTIAL OF SOUTH ANDEAN \\ INTER-NODAL ARCHAEOLOGY
}

Axel E. Nielsen ${ }^{1}$

\begin{abstract}
Resumen
Se discuten los principales conceptos y temas de investigación que caracterizan a la "arqueología internodal sur andina", destacando algunas de sus contribuciones y sugiriendo posibilidades para su desarrollo futuro. Estos puntos se ilustran a través de los aportes reunidos en este volumen y otros que han sido publicados durante las últimas décadas. Teniendo en cuenta los avances realizados, se concluye que la arqueología internodal se ha convertido en un programa de investigación con premisas, métodos y objetivos propios.
\end{abstract}

Palabras claves: Arqueología internodal - interacción interregional análisis de redes - caravanas - tráfico - circulación de bienes sur andino. The main concepts and research topics that characterize the "South Andean Internodal Archaeology", highlighting some of its contributions and suggesting possibilities for its future development. These points are illustrated through the papers assembled in this volume and others published during the past few decades. Considering the advances that have been made thus far, it is concluded that Internodal Archaeology has grown to become a research program with its own premises, methods, and goals.

Keywords: Internodal archaeology - interregional interaction - social networks analysis - caravans - traffic - circulation of goods -Southern Andes.

Recibido: agosto 2017. Aceptado: septiembre 2017 .

1 CONICET; Instituto Nacional de Antropología y Pensamiento Latinoamericano. Calle 3 de Febrero 1378, Buenos Aires, ARGENTINA. Email: axelnielsen@gmail.com

\section{* LA MiRAda inTERNODAL}

En su Postmodern Geographies, Edward Soja (1993) propuso la existencia de un principio de "nodalidad de la vida social", según el cual las actividades e interacciones humanas tenderían a agruparse en torno a nodos o centros geográficos reconocibles. La nodalidad, de acuerdo a este autor, sería una condición existencial de la socialidad humana resultante de los esfuerzos individuales y colectivos por enfrentar la fricción que la distancia impone al estaren-el-mundo. Según este principio, la matriz espacial del mundo de la vida estaría siempre formada por un sistema estratificado de regiones nodales socialmente constituidas, una configuración anidada de locales diferenciados y jerárquicamente organizados, cuyas formas y funciones específicas varían significativamente según el lugar y la época (Soja 1993: 148-149).

A partir del principio de nodalidad podría postularse la existencia de un "principio de internodalidad", según el cual los mismos mecanismos generarían, entre nodos, áreas donde las actividades e interacciones humanas son menos diversas, poco frecuentes, efímeras o inexistentes. Si usamos la red como metáfora, serían los vectores entre vértices, si preferimos la malla (Ingold 2007), serían las líneas solitarias o las áreas atravesadas por una baja densidad de líneas independientes, relativamente diferentes de los nudos y grandes enredos que sostienen la trama. $\mathrm{Al}$ igual que los nodos, los espacios internodales -o "internodos"- varían significativamente en sus formas y funciones. Pueden ser lugares con poca población, deshabitados o hasta sistemáticamente evitados; a menudo se 
trata de áreas desprovistas de recursos o con climas hostiles tales como desiertos, cadenas montañosas, salares o grandes cuerpos de agua, aunque zonas naturalmente ricas en recursos también pueden convertirse en internodos por razones puramente políticas, como sucede con las tierras de nadie en circunstancias bélicas o ciertas áreas de frontera. En casos extremos pueden ser barreras infranqueables para las tecnologías disponibles, aunque por lo general son lugares de tránsito y circulación de personas, bienes e información. El carácter anidado de la nodalidad implica también que los espacios internodales varían según la escala de análisis, pudiendo ser regiones enteras al abordar preguntas de alcance macrorregional o áreas entre ciudades, aldeas, viviendas, campamentos u otros lugares de uso recurrente, al considerar la espacialidad regional o local.

El enfoque internodal propone abordar distintos aspectos de la vida social a partir del análisis de esos espacios intermedios y sus significados, de las prácticas allí desarrolladas, así como de los agentes y la cultura material involucrados. Podría caracterizarse como un ejercicio de pensamiento lateral que busca contribuir a la comprensión de los fenómenos sociales y su espacialidad, asumiendo una perspectiva descentrada, poco familiar, con el propósito de visibilizar de este modo aspectos que pasan inadvertidos a la mirada habitual y naturalizada que tiende a situarse en los nodos. En este sentido, su valor es fundamentalmente heurístico. Como tal, resulta compatible con diversos marcos teóricos, contextos históricos y metodologías y potencialmente es aplicable a innumerables problemas y escalas de investigación, en la medida en que la espacialidad de los fenómenos en cuestión pueda ser representada provechosamente como una red de nodos y áreas interpuestas.

Como estrategia de investigación, la "arqueología internodal" surge en torno a preguntas sobre la historia del tráfico interregional en los Andes circumpuneños, aunque como lo demuestran los artículos reunidos en esta compilación, sus alcances se han ampliado en los últimos años para involucrar a otras disciplinas (historia, etnografía) y encarar nuevas preguntas relativas a la movilidad, la explotación de recursos, la territorialidad y el paisaje, entre otras (véanse ejemplos en Berenguer y Pimentel 2010; Núñez y Nielsen 2011). La asociación de la arqueología internodal con el sur andino no es casual. Por una parte, revela la sostenida importancia que le ha sido dada a la circulación de bienes y la interacción interregional en la arqueología regional (Albeck 1994; Lechtman 2006; Núñez y Dillehay 1979, entre otros). Pero también obedece a las características de su geografía, dominada por desiertos hiperáridos, altiplanicies heladas y accidentes montañosos. Las condiciones hostiles que reinan en estas áreas las convierten en internodos persistentes, donde los rastros materiales de actividades internodales son relativamente visibles y se encuentran excepcionalmente bien conservados, por lo que ofrecen una alta resolución "temporal y conductual", en los términos empleados en estas páginas por Berberena y colaboradores. Esto ha facilitado considerablemente el hallazgo e interpretación de este tipo de evidencias, además de ofrecer un verdadero "laboratorio" - según la metáfora que emplean varios autores en este volumen- donde ensayar distintos métodos para identificar, documentar e interrogar el registro internodal.

Barberena et al. ${ }^{2}$ nos recuerdan que, en los últimos años, estrategias de investigación similares han surgido paralelamente en la Patagonia -también una geografía con fuertes contrastes en la oferta de recursos-, donde partiendo de un enfoque biogeográfico, otros colegas vienen estudiando distintos procesos regionales a partir de conceptos semejantes. Esta convergencia es sugerente. Podría ser entendida como parte del auge que han cobrado en las ciencias sociales durante los últimos años corrientes teóricas que conciben a la sociedad como red (Borgatti et al. 2009), poniendo énfasis en las relaciones entre unidades sociales de distinto tipo (personas, grupos, localidades, poblados) y en los patrones que surgen de ellas (Brughmans 2013). El impacto de este tipo de pensamiento en la arqueología se reconoce a distintos niveles, desde la creciente popularidad de teorías "relacionales" como el actor-network theory o ANT (p.e., Latour 2005) hasta la aplicación de métodos inspirados en el social network analysis (SNA) a la investigación del intercambio, las migraciones, la identidad, la territorialidad y los "enredos materiales", entre otros temas, en contextos que varían desde cazadores-recolectores hasta imperios (Collar et al. 2015; Gjiesfjield 2015; Hodder y Mol 2016; Knappett 2011; Mills et al. 2015; Smith 2007).

\footnotetext{
2 La mención de autores sin año de publicación refiere a trabajos incluidos en este volumen.
} 
Lo que distingue al enfoque internodal de otros modos de encarar el estudio de redes, es el énfasis puesto en la investigación directa de estos espacios bajo la premisa de que pueden proporcionar información diferente y complementaria a la que ofrecen los nodos y que esta información puede ser relevante para entender aspectos de la sociedad en su conjunto. En este sentido, es importante destacar que los internodos no son necesariamente espacios vacíos o ignorados, sino una clase de lugares que la vida social siempre genera y que, dada su situación, potencialmente comparten características que los estudios internodales buscan establecer $y$, en lo posible, modelizar. Se trata de posicionar la mirada en los internodos para indagar sus propiedades distintivas, los principios que rigen las prácticas allí situadas y las lógicas que animan a sus protagonistas, buscando entender cómo intervienen en la constitución de la sociedad mayor. El principal desafío metodológico que plantea este enfoque a la arqueología es cómo aprovechar la evidencia material de los espacios y prácticas internodales para poner en riesgo distintas proposiciones sobre la naturaleza y organización de las redes sociales y sus procesos de transformación. Así entendida, la arqueología internodal es una estrategia distinta, aunque evidentemente complementaria de las habitualmente empleadas en este campo de estudio.

En las siguientes páginas aprovecho los aportes que realizan los autores en este volumen para discutir ciertos conceptos y ejes de investigación que están surgiendo en el marco de la arqueología internodal sur andina, ${ }^{3}$ sintetizar algunos avances y señalar posibilidades a futuro. Queda pendiente considerar sus distintivos desafíos metodológicos, pero el lector encontrará propuestas substanciales al respecto en varios trabajos (Barberena et al.; Borie et al.; Pimentel et al.).

3 Utilizo esta categoría en forma deliberadamente vaga para aludir a un área de límites flexibles, situada al sur de los Andes centrales (área de surgimiento de Estados prehispánicos), donde las particularidades de la cordillera gravitan significativamente en los procesos sociales, resultando en problemáticas distintivas y ampliamente compartidas en el espacio y el tiempo. También empleo cuando es preciso conceptos más acotados, como Andes circumpuneños o norpatagónicos.

\section{* La internodalidad como condición social, DINÁMICA Y RELATIVA}

Como señalan Barberena et al., la distribución que presentan recursos claves para distintos tipos de actividades y sus variaciones en el tiempo (p.e., a escalas estacionales, interanuales o mayores) es un punto de partida fundamental para encarar investigaciones arqueológicas en un área desde la perspectiva internodal. En primer lugar, esta información permite identificar lo que serían potencialmente espacios internodales en función de diferentes estrategias de ocupación del espacio. Pero también es importante porque variables tales como el grado de contraste en la distribución de recursos condicionan la redundancia que muestra la configuración geográfica de nodos e internodos y, por lo tanto, las posibilidades de aislar analíticamente el componente internodal en un registro material acumulado en períodos prolongados. En principio, áreas con distribuciones de recursos relativamente homogéneas generan baja redundancia en el posicionamiento de nodos e internodos, lo que, a largo plazo, dificulta la identificación de estos últimos y del registro arqueológico de baja densidad que los caracteriza. Por el contrario, cuando se encuentran altamente concentrados, como ocurre en zonas áridas, la falta de recursos en extensas áreas desalienta ocupaciones más o menos permanentes o intensivas que obliterarían las ligeras evidencias de actividades internodales. Sería prematuro concluir que la arqueología internodal solo es viable en regiones de marcados contrastes, pero resulta claro que esta variable condiciona los problemas metodológicos que un enfoque de este tipo enfrenta en distintos contextos ambientales.

En este punto, sin embargo, conviene enfatizar que nodos e internodos son resultado de la espacialidad de las prácticas, no características esenciales de la geografía. Esto significa que, aunque su configuración necesariamente guarda relación con el sustrato biogeográfico, especialmente con la distribución de recursos como el agua y la biomasa (Yacobaccio 1994), siempre se constituye socialmente y con referencia a condiciones demográficas, capacidades tecnológicas y logísticas, normas de convivencia, relaciones de poder, valores, memorias y cosmologías, entre otros aspectos que dependen del contexto socio-histórico. Esto último es válido aun para procesos de escala temporal larga, como el poblamiento, ya que las 
cambiantes condiciones demográficas vigentes en distintas etapas del mismo - desde la exploración hasta la ocupación efectiva - generarían distintas configuraciones de lugares nodales e internodales en los mismos escenarios biogeográficos, abarcando siempre áreas con buena oferta de recursos pero sin presencia humana significativa (internodos), incluso en épocas recientes si, como enfatiza Borrero (2015: 132), la población nunca llegó a saturar el continente.

En escalas más breves, zonas hostiles también pueden desarrollar importantes nodos. Pongamos por caso los Andes circumpuneños, donde los recursos claves para la subsistencia se mantuvieron concentrados en bolsones discretos separados por vastos espacios hostiles o escasamente productivos (desiertos, cordilleras), una configuración biogeográfica contrastada que se mantuvo vigente a lo largo de todo el Holoceno, aunque con variaciones de intensidad (Núñez et al. 2005; Yacobaccio 2013). Como sería de esperar, en distintas épocas este escenario se tradujo en espacialidades marcadamente "nodalizadas", con fuertes contrastes en la densidad de actividades e interacciones. Gil Montero et al. dan cuenta de la fortaleza de este patrón en el largo plazo al señalar que, a pesar de las grandes transformaciones que supuso la invasión europea, las visitas del siglo XVII -el peor momento en la caída demográfica provocada por la conquista- registran los mismos nodos de población que, según la arqueología, caracterizaron el área por milenios. Pero los mismos autores muestran cómo esta estructura natural fue desafiada coyunturalmente por la administración colonial española al instalar la urbe minera de San Antonio en plena cordillera de Lípez, un área que antes y después del siglo XVII funcionó solamente como lugar de tránsito, caza o pastoreo estacional. El ejemplo pone de relieve, en primer lugar, la incidencia que tienen las tecnologías de transporte y las capacidades logísticas en la configuración de nodos e internodos, pero también nos recuerda que muchos "recursos claves" - por ejemplo, la plata- no están directamente vinculados a la subsistencia tal como la entendemos desde el sentido común, sino que se definen socialmente en función de valores y cosmovisiones particulares y cambiantes en escalas temporales relativamente breves. Retomaré estos puntos más adelante.

Si uno pone el foco en estas escalas temporales seculares, ciertos espacios asumen carácter nodal o internodal no por los recursos que ofrecen, sino por su condición geopolítica o por lo que significan. Así sucede cuando se abandonan zonas productivas para crear áreas de amortiguación - "tierras de nadie" ${ }^{4}$ - en épocas de conflicto o cuando se desarrollan nodos en lugares desprovistos de recursos propios, pero significativos en términos religiosos o por su vinculación con la memoria social. Como ejemplo de la primera situación, se ha propuesto que la inseguridad resultante de los conflictos endémicos de los siglos XIII a XV en los Andes circumpuneños provocó la desaparición de sitios residenciales permanentes que habían prosperado hasta entonces en las tierras altas de la quebrada de Humahuaca, provocando una nodalización del paisaje que tuvo considerables consecuencias políticas (Nielsen 2001). El actual santuario de la Difunta Correa, un importante nodo de peregrinación y acumulación de ofrendas en pleno desierto de San Juan, ilustra claramente la segunda posibilidad. Allí se conmemora un evento milagroso típicamente internodal, la supervivencia de un bebé cuya madre -Deolinda Correa- falleció de sed y agotamiento mientras intentaba cruzar el despoblado en busca de su marido, reclutado forzosamente por la soldadesca durante las guerras civiles de la primera mitad del siglo XIX (Chertudi y Newbery 1966-67).

Conviene además enfatizar que los conceptos de nodo e internodo designan extremos en una dimensión de la espacialidad que varía de formas complejas y siempre admite estados intermedios, por lo que deben ser aplicados en forma flexible, según la escala y las preguntas de investigación. Volviendo al caso del Período Colonial en los Andes circumpuneños, los nodos que identifican Gil Montero et al. son las regiones con mayor potencial agrícola relativo, tratando como internodos a los espacios intermedios, que comprenden zonas desprovistas de asentamientos permanentes, como las lagunas altoandinas o la cordillera occidental, pero también otras -el sureste de Lípez o la puna occidental, por ejemploocupadas de forma dispersa por pastores especializados, habitantes internodales permanentes desde esta perspectiva. Este planteo es apropiado a sus objetivos, ya que las comunidades conglomeradas y políticamente integradas características de las áreas agrícolas fueron el foco de las

4 Nótese que en esta escala la expresión refiere a lugares vedados a todos dada la intensidad del conflicto bélico, mientras que en la perspectiva biogeográfica (Barberena et al.) designa espacios abiertos a cualquiera por su baja conflictividad. 
políticas tributarias y de control de la población, que dieron origen a sus fuentes, además de actuar como nodos de consumo. Pero si se investigara el mismo espacio en función de la producción ganadera, sería preciso tratar también como nodos los territorios de pastores, y si las preguntas estuvieran referidas a la organización de estos últimos, cobrarían importancia estancias y pequeños caseríos que operan como nodos en los itinerarios de la vida pastoril, separados por grandes espacios donde las actividades son más efímeras y las interacciones poco frecuentes.

\section{* El tránsito en los internodos}

El tránsito es una de las principales actividades desarrolladas en los espacios internodales. Por cierto, su estudio arqueológico no es nuevo en los Andes, donde existe, por ejemplo, una importante tradición de investigaciones sobre el camino Inca. Lo que la arqueología internodal ha puesto de manifiesto, no obstante, es que la evidencia arqueológica del tránsito internodal no se limita a los sistemas viales formalizados construidos por el Tawantinsuyu o los Estados nacionales, sino que comprende un denso registro de senderos, paraderos, sitios rituales, marcas, tumbas y otras evidencias acumuladas durante milenios que pueden brindar información valiosa sobre la historia de la circulación y de las relaciones entre grupos. Después de todo, la definición de vías de tránsito, por informales que sean, puede considerarse un aspecto fundamental de la ocupación efectiva de cualquier región (sensu Borrero 1994-1995), lo que significa que en la mayor parte del sur andino los "paisajes de tránsito" tienen una historia prolongada en la que la construcción de sistemas formales de caminos (sensu Trombold 1991) fueron solo episodios breves y relativamente recientes.

Por lo general, las vías informales solamente cobran visibilidad arqueológica en zonas áridas o cuando la intensidad de su uso produce modificaciones tales que permiten reconocerlas a pesar de la vegetación y la actividad geomorfológica. En tales casos, ciertas características "micromorfológicas" de las vías (Trombold 1991) permiten diferenciar categorías de usuarios en términos del tamaño y composición de los grupos que las transitaron y las tecnologías de transporte utilizadas. De este modo, se ha propuesto que los grupos costeros que recorrían el desierto de Atacama lo hacían en contingentes reducidos que dejaron sendas únicas, mientras que los pastores del interior y las tierras altas, que frecuentemente viajaban con caravanas de llamas, produjeron senderos más amplios de múltiples huellas entrelazadas (Berenguer et al. 2005; Pimentel et al. 2011). La introducción de las mulas y otros equinos en tiempos históricos, por su parte, generó senderos de huellas paralelas debido al modo de andar característico de estos animales. Posteriormente, las carretas agregaron sus marcas distintivas a las rutas y los arreos de ganado europeo las marcaron con las amplias rastrilladas como las que Berón et al. describen para la región pampeana. Blanco et al. emplean estas categorías para organizar su diseño de prospección en el internodo Quillagua-costa, muestreando una vía costera y una caravanera, mientras que Martel et al. las utilizan para diferenciar rutas anteriores y posteriores al contacto europeo en la pampa de Carachi, al sur de Antofagasta de la Sierra.

Cuando su visibilidad arqueológica lo permite, el estudio macromorfológico de las vías puede informar sobre diversos temas, incluyendo por ejemplo, la cambiante jerarquía de distintos tramos o sectores de la red, la importancia de ciertos flujos económicos o la existencia de nodos aún no reconocidos como tales o cuya impronta arqueológica ha desaparecido por ocupaciones recientes, como ocurre con las sendas que convergen hacia distintos puntos de la costa (Blanco et al.; Núñez y Briones; Pimentel et al. 2011). Por cierto, el trazado de las vías no solo obedece a motivaciones económicas o utilitarias (Curtoni 2007), sino que también conecta lugares de especial relevancia cosmológica, como sostienen González et al. al argumentar que la configuración de la vialidad incaica en Mina Las Turquesas no solo obedeció al interés del Tawantinsuyu por apropiarse de la producción lapidaria, sino que se orientaba especialmente a incorporar en su esfera política a una importante wak'a regional, el cerro Indio Muerto. Más aún, las redes viales no solo reflejan lo valorado en distintas épocas, sino que estructuran activamente esas cosmovisiones al situar la mirada de los transeúntes y moldear su experiencia (Ingold 1993), de allí su importancia ideológica.

Las vías se encuentran jalonadas por paraderos, lugares donde los viajeros se detienen a descansar por lapsos que varían entre pocas horas y varios días. Dependiendo de su duración, estas paradas pueden incluir la preparación 
y consumo de alimentos, la reparación de equipos, el descanso nocturno, la interacción con las deidades y hasta funerales para los fallecidos en ruta. Lugares reiteradamente utilizados con estos fines generan sitios arqueológicos de considerable visibilidad, que se conocen etnográficamente como paskanas (Chile), jaranas (Bolivia), realeros (Argentina) o, sencillamente, "alojamientos" (Nielsen 1997). A menudo estos campamentos aprovechan reparos naturales o estructuras abandonadas construidas originalmente con otro propósito. La mayoría de ellos se levanta informalmente a través de innumerables adiciones realizadas expeditivamente por los propios viajeros, aunque su acondicionamiento y estandarización es una de las intervenciones características asociadas a la formalización de los sistemas viales por parte de los Estados, como lo ejemplifican los albergues a la vera del Qhapaq Nan (tambillos, chaskiwasis), las postas camineras erigidas por Bolivia (Sanhueza 2011) o los refugios de arrieros construidos a fines del siglo XIX por el Gobierno en ámbitos cordilleranos del centro-oeste argentino (Bárcena, com. pers. 2017). Por estas razones, los paraderos se encuentran entre los escenarios internodales más fructíferos para la investigación de la historia del tránsito.

Los trabajos de este volumen ofrecen un buen panorama de la ubicuidad y variabilidad que ostentan los alojamientos informales en rutas que van desde la Puna hasta la costa del océano Pacífico. Las estructuras de refugio comprenden sencillas depresiones cavadas en el suelo, paravientos bajos de pirca seca, pequeños recintos irregulares o rocas y afloramientos existentes, a veces mejorados con la adición de algún muro. Puede tratarse de estructuras aisladas o sumar decenas en el mismo sitio. Las extraordinarias condiciones de preservación que reinan en el desierto de Atacama permiten atisbar la enorme diversidad de desechos que llegan a acumularse en estos campamentos, incluyendo, además de cerámica y material lítico, restos de moluscos, pescado, mamíferos y aves, madera, frutos, calabazas, guano, minerales, cordeles y tejidos, entre muchos otros que describen Núñez y Briones o Pimentel et al. En la mayoría de los internodos, sin embargo, los materiales perecederos desaparecen, lo que plantea la necesidad de recurrir a otros tipos de evidencias, como lo hacen Martel et al., quienes recuperan durante la excavación de un recinto circular directamente asociado a los senderos, fitolitos de maíz y tubérculos, además de esferulitas que delatan la presencia de caméli- dos en la ruta. El registro arqueológico de los paraderos permite abordar diversas interrogantes sobre el tránsito y sus relaciones con el contexto social mayor, por ejemplo, la procedencia y estrategias de aprovisionamiento de los viajeros, la naturaleza de los bienes transportados o las cuencas de tráfico asociadas a distintos tramos de las rutas (Martel et al.; Nielsen 2013; Pimentel et al. 2011), entre otras.

Es frecuente que los sitios de pernocta sean reiteradamente utilizados a lo largo del tiempo, como lo ilustra Calate 2, una paskana con substanciales ocupaciones del Período Formativo, pero con niveles iniciales datados en el Arcaico Medio (Pimentel et al.); o Aguas Calientes 1 con cerámicas correspondientes a todos los períodos prehispánicos de la Puna meridional (Martel 2014; Martel et al.). Esto resulta en la frecuente yuxtaposición dentro de las mismas estructuras (Briones et al. 2005), incluso en los mismos depósitos, de residuos generados por ocupaciones distanciadas por siglos o milenios, lo que obliga a ser cautos al momento de postular asociaciones entre materiales o eventos en estos contextos. Para entender este fenómeno hay que considerar las restricciones de tiempo con las que operan generalmente los viajeros, que les impiden demorarse en la construcción o acondicionamiento de los lugares de descanso y los obliga a aprovechar cualquier forma de reparo disponible donde los sorprenda el final de la jornada. Esta lógica oportunista convierte los abrigos naturales, estructuras abandonadas - cualquiera haya sido su función original- y campamentos ya existentes en verdaderos "atractores" de viajeros y da cuenta de la redundancia ocupacional y persistencia que caracteriza a muchos de estos sitios.

Teniendo en mente estos recaudos, el estudio pormenorizado de ciertos paraderos puede dar abundante información sobre la microhistoria del tránsito en una región, como lo ilustra el artículo de Berenguer \& Salazar sobre Incaguasi y su cambiante papel en las travesías del Loa superior durante el último milenio. Combinando evidencias arquitectónicas, estratigráficas y artefactuales con fuentes escritas y testimonios orales, recrean la biografía de este lugar que sirvió alternativamente de paskana, tambillo, posta y corral. Resulta interesante que la inversión arquitectónica allí realizada por el Tawantinsuyu atrajera en forma duradera a los transeúntes en busca de reparo, a pesar de sufrir incendios y terremotos y de que el sitio 
fuera relegado a una posición marginal por las políticas estatales durante los períodos colonial y republicano. El estudio revela la presencia de actividades pocas veces imaginadas en contextos de tránsito, como la fundición de metales, al tiempo que brinda elementos para pensar las formas en que se hacen efectivas las jerarquías sociales en contextos internodales, al señalar el contraste entre quienes -en la misma época- pernoctaban en el cómodo albergue aprovisionado por el Estado inca y quienes acampaban junto a los precarios paravientos de la paskana adyacente.

\section{* La extracción de Recursos}

La presencia de recursos valiosos lejos de las áreas más densamente pobladas hace de su extracción otra actividad relativamente común en espacios internodales. Uno de tales recursos es, evidentemente, la fauna silvestre, sencillamente porque la perturbación que conlleva la intensa actividad humana propia de los nodos -especialmente en contextos sedentarios- provoca su retracción hacia ámbitos intersticiales. Esto hace que la caza sea una actividad típicamente internodal, un hecho que podría dar cuenta de ciertas connotaciones simbólicas que a veces asumen esos lugares (p.e., Bouysse-Cassagne y Harris 1987).

Con frecuencia, la caza es el principal motivo que atrae a ciertos contingentes temporariamente hacia los internodos, movilidad que puede estar organizada de diferentes formas y dejar improntas arqueológicas distintas. Las familias viviendo en la margen oriental del salar de Atacama a principios del siglo XX, que según Bowman (1924: 268-270) dejaban casi vacíos sus pueblos a fines del verano para trasladarse a la región altoandina a cazar colectivamente vicuñas, ejemplifican estrategias de movimiento residencial. La vigencia de prácticas similares desde el primer milenio d.C. -por lo menos- ha sido verificada arqueológicamente en ese elevado internodo lacustre a través del hallazgo de verdaderas aldeas con varios complejos residenciales sólidamente edificados, posiblemente habitadas de forma temporaria por grupos domésticos (p.e., Ojo del Novillito, Puerta de Chillagüita y Chillagua Grande [Nielsen et al. 2010]). Otros sitios contemporáneos en la misma región, en cambio, parecen ser simples campamentos como los que podrían ocupar reducidas fuerzas de tareas procedentes de nodos distantes operando bajo principios logísticos (p.e., Laguna Hedionda con cerámica Mallku del norte de Lípez [Barfield 1961] entre otros [Nielsen et al. 1999]). Pero la caza también fue una importante fuente de provisiones para quienes llegaban a espacios internodales en busca de otros recursos (p.e., los antiguos pirquineros de Mina Las Turquesas que ocasionalmente consumían roedores y cérvidos [González et al.]) o para quienes solo los transitaban, como ocurrió en alojamientos asociados al camino Inca de la cordillera occidental (p.e., Tambo Cañapa), donde la fauna silvestre predomina absolutamente en los desechos (Nielsen et al. 2010).

El aprovechamiento de plantas silvestres más o menos concentradas (algarrobales, áreas de pastoreo) es otra razón que atrae a la gente temporariamente hacia espacios internodales, como lo ilustran los puestos pastoriles registrados por Martel et al. en Aguas Calientes, al norte de Antofagasta de la Sierra. Este uso pastoril intermitente parece haber sido bastante común durante el Período de Desarrollos Regionales en los internodos altos que rodean las grandes quebradas del flanco andino oriental, como Humahuaca o San Juan Mayo (Nielsen 2001; Nielsen et al. 2015). Allí el pastoreo se integraría bien con la caza para formar un mismo programa de trabajo diversificado.

Rocas y minerales son otra clase de recursos explotados con frecuencia en ámbitos internodales, una actividad cuya escala, organización y rastro arqueológico merecen ser explorados. El cotejo de los casos aquí presentados permite señalar por lo menos tres factores relevantes para pensar esta variabilidad en zonas desprovistas de recursos fundamentales para la vida, como agua y alimentos. Estos son: el valor de los materiales extraídos, las tecnologías de transporte disponibles y el financiamiento, es decir, la capacidad de movilizar mano de obra y excedentes para sustentarla. Las rocas silíceas trabajadas en varios paraderos asociados a senderos de grupos costeros (Blanco et al.; Pimentel et al.) o los talleres y campamentos detectados en distintos puntos de la Depresión Intermedia al interior de Taltal (Borie et al.) ofrecen un buen punto de partida. Algunos de esos talleres se ubican a casi $100 \mathrm{~km}$ del mar; teniendo en cuenta las características extremas de este desierto, atravesarlo es una proeza que invita a pensar cómo se transmitió por milenios el conocimiento de los ínfimos pero vitales recursos presentes en un espacio de 
semejantes proporciones. Todo esto no deja dudas sobre el alto valor que tuvieron estas materias primas para las comunidades residentes en el litoral, donde no contaban con rocas de semejante calidad para la talla.

Más al norte, entre Quillagua y la costa, Blanco et al. descubren a una jornada del litoral extensas minas de yeso trabajadas con simples rodados y palas de conchas marinas por grupos de tareas que pernoctaban en precarios refugios cavados en el suelo entre 4 y más de 6 mil años antes del presente. Este hallazgo demuestra, nuevamente, la sorprendente capacidad que tuvieron reducidos grupos de cazadores-recolectores del litoral para internarse varios días en espacios hiperáridos en busca de materiales que debían cargar de vuelta a sus espaldas. Los riesgos que esto suponía también dejan claro que el yeso era un recurso clave para los pueblos de la costa, pero curiosamente los autores encuentran dificultades para decidir cuál pudo ser el uso o significado que tuvo esta substancia, a pesar de contar con interesantes alternativas etnográficas (no excluyentes), desde la geofagia hasta la pintura corporal. Más allá de la respuesta que futuros estudios puedan dar a esta interrogante, el caso nos advierte sobre la conveniencia de desechar las dicotomías modernas que habitualmente se usan en arqueología para discutir el valor de los bienes y sus consecuencias prácticas, p.e., subsistencia-prestigio/riqueza, materialsimbólico, etcétera (Gallardo y Cabello 2015; Lazzari 2016; Nielsen 2007). En todo caso, las limitaciones de su tecnología de transporte -aun teniendo en cuenta la eventual introducción del portacargas - y la falta de apoyo logístico pusieron coto a la escala de las explotaciones internodales encaradas por los grupos costeros.

La investigación de González et al. en Mina Las Turquesas, hacia el sur del despoblado de Atacama, revela el progresivo desarrollo que experimentó allí la extracción de rocas de color a lo largo de dos milenios, hasta convertirse en una operación de magnitud diferente a las comentadas hasta aquí. A lo largo de toda la secuencia, este material fue trabajado in situ para confeccionar cuentas y figurillas, productos que circulaban ampliamente para

5 Este artificio de transporte pudo ser incorporado ocasionalmente por otros grupos, como lo sugiere el hallazgo por obra de un vecino de varias partes de un portacargas escalerado en una cueva cercana al salar de Uyuni, exhibidas actualmente en el denominado "Museo Muy Interesante" de Aguaquiza (Nor Lípez). servir de ornamento, acompañamiento para los difuntos, moneda de pago en las ofrendas o alimento de las divinidades, entre otros usos. La extracción comenzó durante el Formativo a través de visitas breves, aumentó en el Período Medio, cuando las ocupaciones se volvieron más estables y, para el Intermedio Tardío, llegó a convertirse, posiblemente, en una verdadera colonia productiva y artesanal, a juzgar por la magnitud de los desechos y el cementerio asociados. Las distancias que separan este enclave de las aguadas y oasis agro-pastoriles más próximos (10 y $50 \mathrm{~km}$, respectivamente) plantean problemas de aprovisionamiento que solo pudieron resolverse gracias a la capacidad de transporte provista por las caravanas de llamas, cuya presencia está abundantemente testimoniada en los depósitos excavados (huesos, fibra, iconografía) y en las vías que llegan al lugar.

La formación del Tawantinsuyu no produjo en Mina Las Turquesas un salto de escala comparable al registrado en otras localidades del desierto donde se advierte una transformación radical en la magnitud y organización de las explotaciones a partir de la intervención inca (Núñez 1999; Salazar 2008). En San José del Abra, por ejemplo, la minería pasó de ser una actividad intermitente de familias pastoriles del Alto Loa en el PIT, a una operación permanente a cargo de colonias de mitayos atacameños reclutados en distintas comunidades de la región, que se alternaban para la producción masiva de cobre y turquesa, apoyada por caravanas de llamas que proveían regularmente los insumos y provisiones necesarios desde los almacenes estatales y transportaban el mineral seleccionado para su procesamiento lapidario o metalúrgico en otras localidades (Salazar 2008). Este caso pone de relieve la tercera variable mencionada anteriormente: una economía capaz de movilizar gran cantidad de mano de obra y los excedentes necesarios para aprovisionarla.

San Antonio de Lípez (Gil Montero et al.), de proporciones urbanas, representa un salto más en la escala de estos emprendimientos extractivos. Los sistemas de transporte combinaban allí camélidos, equinos y vehículos de rueda; la economía que lo financiaba movilizaba trabajadores y bastimentos de un área tan extensa que alcanzaba hasta el Cuzco (Gil Montero 2011: 300); y, sobre todo, se enmarcaba en un capitalismo mercantil de escala global que investía a la plata obtenida de un valor extraordinario, justificando presuntamente el esfuerzo. 


\section{* Perspectivas descentradas sobre la CIRCULACIÓN DE BIENES}

El tráfico interregional y sus consecuencias sociales ha sido uno de los temas más persistentes y debatidos de la arqueología surandina. Desde la mirada internodal pueden realizarse aportes substanciales a este campo de estudio, principalmente identificando las prácticas y agentes específicos que dan cuenta de la circulación de distintos bienes entre nodos ${ }^{6}$ en cada época y lugar. Esta información puede resultar crucial para poner a prueba modelos generales que relacionan el tráfico con distintos procesos económicos, políticos o culturales. Para ello, es importante avanzar en la definición de modalidades de circulación regidas por diferentes mecanismos y sometidas a distintas condiciones sociales y enredos materiales (Hodder 2012). A diferencia de otras propuestas que ya existen en relación al intercambio ampliamente entendido (p.e, Renfrew 1975), estas categorías deberían desarrollarse a partir de registros arqueológicos específicamente internodales.

La clásica distinción entre formas directas e indirectas de provisión de bienes en contextos de cazadores-recolectores ofrece un punto de partida para sistematizar las formas de circulación de bienes desde esta perspectiva. Elementos foráneos pudieron llegar a los nodos, en primer lugar, por aprovisionamiento directo, mediante la acción de personas locales que los obtuvieron directamente en internodos cercanos. En el desierto atacameño, la adquisión de sílices y yeso por parte de grupos costeros, así como la de andesitas por parte de caravaneros, ilustra bien esta modalidad (Blanco et al., Borie et al.). Podría reservarse el concepto de tráfico, entonces, para formas de aprovisionamiento indirecto, que involucran intercambios u otros tipos de acuerdos -p.e., permisos de extracción- entre grupos diferentes, abriendo así un nuevo campo de posibilidades para la negociación de las relaciones sociales.?

6 Circulación designa solamente el movimiento de cosas entre puntos geográficamente reconocibles, sin referencia a los mecanismos o actividades involucrados.

7 Tráfico designaría, entonces, una modalidad de circulación que conlleva intercambios, traspaso de bienes entre grupos u otros agentes sociales y, por lo tanto, algún tipo de negociación. La naturaleza de estas transacciones y sus consecuencias requiere otras categorías cuyo tratamiento excede los alcances de este trabajo pero es relevante para una arqueología internodal.
Al respecto, se ha propuesto una distinción entre tráfico especializado, cuando el traslado y transacción de bienes es el principal objetivo del viaje, e incorporado, cuando éstos se encuentran subsumidos en otras cadenas operativas con sus propias lógicas de movilidad, escenarios y programas de trabajo (Nielsen 2006).

Varias contribuciones aquí muestran la importancia y complejidad del tráfico especializado y su registro internodal. Se identifican contingentes costeros llegando a los oasis a obtener algarrobo y maíz, entre otros productos, y también del interior, viajando hasta la costa acompañados por animales de carga para conseguir productos del mar (Núñez y Briones; Pimentel et al.). Los caravaneros que pernoctaban en Incaguasi durante el Intermedio Tardío posiblemente traficaban los metales que allí fundían hacia otros nodos del Loa superior o más allá (Berenguer y Salazar). En los oasis puneños, Martel et al. siguen el rastro de caravanas que llevan hacia distintos valles cerámicas o materiales líticos - entre otros bienes por determinar- según las preferencias de las comunidades de destino.

Sitios extractivos como Las Turquesas y San Antonio de Lípez, en cambio, ilustran escenarios de tráfico incorporado subsumidos en operaciones minero-metalúrgicas (Gil Montero et al.; González et al.). La convergencia de gente de distinto origen a estos lugares indudablemente creó oportunidades de intercambio de bienes que, a su vez, serían llevados a otros nodos donde eventualmente serían desechados. Aquí es importante enfatizar la flexibilidad que requiere analizar estos escenarios extractivos, que pueden ser tratados como nodos o parajes internodales, según su envergadura y las preguntas de investigación. En época formativa parece claro que los grupos de tareas que visitaban Las Turquesas se encontraban en situación internodal, pero en tiempos tardíos habitaban un enclave cuya demanda atraía un significativo flujo de bienes distantes (ganado, productos agrícolas y marinos, cerámica y otras manufacturas, etc.) que se descartaban en el lugar, permitiendo pensarlo como nodo en función de esta circulación y de estos fenómenos de consumo. San Antonio, en cambio, un nodo mercantil de proporciones urbanas en el siglo XVII, es hoy un solitario paradero internodal donde a veces se cruzan turistas, que pueden intercambiar objetos que tal vez lleven consigo al regresar a sus lugares de origen. 
Este último ejemplo lleva a pensar otras situaciones de encuentro en los internodos que pueden resultar en tráfico incorporado. Núñez y Briones reconocen otras variantes en el abundante registro internodal del desierto tarapaqueño. Los escenarios asociados a geoglifos que combinan iconografía y ofrendas del litoral y de oasis interiores, por ejemplo, son propicios para transacciones entre costeros y caravaneros estrechamente asociadas al rito. Esta posibilidad cobra una visibilidad arqueológica extraordinaria en Soronal, un reducido humedal salobre situado a $21 \mathrm{~km}$ del mar y 60 de Pica, donde se reunían periódicamente traficantes costeros y caravaneros, generando lo que los autores postulan como un "puerto de tráfico". Allí se encuentran los campamentos donde todos ellos pernoctaban y establecían sus tratos, los bienes de diversa procedencia que consumían e intercambiaban, además de sepulturas, geoglifos y todo tipo de ofrendas (Briones et al. 2005). Este caso desafía una vez más dicotomías habituales en las discusiones sobre movilidad y circulación de bienes. Una de ellas es la implícita en el concepto de "movilidad no-utilitaria" (Whallon 2006). ¿Cómo separar en este escenario -en las escalas temporales de la práctica social al menos- la transacción de bienes (objetos e ideas) necesarios y superfluos o la subsistencia de la socialización entre personas de distinta procedencia y filiación? También pone en evidencia ciertos límites de los conceptos de tráfico especializado e incorporado, toda vez que sería arbitrario decidir si es la lógica del intercambio entre humanos o la del intercambio con no humanos - el rito- la que prevalece en la situación. De hecho, el equilibrio entre estas dos cadenas operativas es un aspecto fundamental de este escenario multiétnico que, posiblemente, amerite la definición de una variante de tráfico que deberíamos rastrear también en otros espacios internodales del sur andino.

Falta tipificar formas violentas de intercambio, como la piratería o el saqueo de asentamientos en tiempos de guerra, así como sus implicancias para el registro arqueológico internodal. Pimentel et al. describen en Calate contextos que evocan la primera de estas prácticas, mientras que Núñez y Briones mencionan al pasar la segunda. También los enfrentamientos entre grupos cazadoresrecolectores, como los que dejaron su impronta en los cuerpos inhumados en cementerios pampeanos como Chenque I, podrían ser responsables de la circulación de algunos de los bienes alóctonos que enumeran Berón et al. en su artículo. Las autoras destacan los conflictos por el control de las rutas de tráfico (rastrilladas y pasos cordilleranos), pero también citan el caso de 200 pehuenches aniquilados por fuerzas rankulches, presuntamente por encontrarse cazando guanacos en cotos de su pertenencia. Por otra parte, es sabido que transacciones violentas eran moneda habitual en la circulación de bienes de origen europeo hacia y entre los territorios indígenas situados allende la frontera colonial hasta fines del siglo XIX (Palermo 2000). ¿Será posible identificar las improntas de algunas de estas formas de hostilidad en los propios espacios internodales, por ejemplo, como acondicionamientos defensivos de posiciones estratégicas a lo largo de ciertas rutas (p.e., Goñi 1987)?

En suma, las contribuciones a este volumen muestran con claridad la existencia en el sur andino de modos de circulación de bienes muy heterogéneos, en los que intervienen todo tipo de escenarios, actores y transacciones. También verifican que varios de ellos estuvieron operando simultáneamente en las mismas áreas y con la participación de las mismas poblaciones, como lo confirman de forma patente las sendas costeras y rastrilladas caravaneras contemporáneas que siguen los mismos derroteros. Este carácter redundante de los sistemas de interacción y circulación en el sur andino (cf. Martínez 1998) ofrece múltiples opciones a las personas para obtener bienes alóctonos y obliga también a sospechar de aquellos modelos que pretenden explicar procesos sociales a partir del control restrictivo y la centralización del tráfico por parte de élites o, incluso, burocracias estatales (Nielsen 2007).

No quisiera concluir esta sección sin mencionar que la vinculación intrínseca entre tráfico e internodos pudo ser una importante fuente del valor de los bienes lejanos, cualquiera haya sido el uso al que estuvieron destinados. El viaje de Ulises, como metáfora de la experiencia de la distancia y las peripecias sufridas para franquearla (Helms 1988), también captura la posibilidad de que las travesías internodales -en todas sus variantes-incorpore una cuota distintiva de valor a los bienes que circulan entre regiones. Ciertamente, el "sufrimiento del viaje" del que tanto hablan los llameros altiplánicos (West 1981) aporta un valor especial a los costales de maíz que traen a sus familias cada año con las caravanas. 


\section{^ Personas y agenciamientos internodales}

La combinación de las distintas líneas de evidencia hasta aquí comentadas (tipos de vías, paraderos, bienes en circulación, etc.) ha permitido a la arqueología internodal avanzar en la identificación de quienes habitaron las áreas intersticiales en términos de su permanencia relativa (transitoria, temporaria), su propósito (pastores, cazadores, mineros, traficantes, guerreros, etc.), su lugar de origen (litoral marino, oasis interiores, altiplano, valles subandinos, llanuras pampeanas) y sus colectivos de pertenencia. Pero ninguno de esos testimonios resiste comparación con el hallazgo de los propios cuerpos de quienes fallecieron en ruta cuando se trata de conocer a los agentes internodales. Este registro, que ya cuenta con decenas de casos, permite explorar innumerables detalles de la vida y muerte de aquellas personas a través de distintos indicadores bioarqueológicos y el análisis de los contextos de inhumación (Cases et al. 2008; Pestle et al. 2015; Torres-Rouff et al. 2012). A través de este tipo de hallazgos, se han calibrado también otras evidencias internodales que hoy poseen valor diacrítico, como las sendas, paraderos y ritos que distinguen a los viajeros costeros (Pimentel et al. 2011).

La información sobre sexo y edad de los viajeros que brinda este registro permite poner a prueba ideas sobre las estrategias de movilidad y supuestos de género que habitualmente se hacen en relación a ellas. Varios casos de hombres adultos en contextos caravaneros ratifican el modelo etnográfico según el cual estos viajes serían propios de hombres y varones jóvenes estrechamente emparentados (Pimentel et al.). Resulta inesperada, en cambio, la presencia de hombres, mujeres y niños de procedencia costera inhumados en Calate, ya que, como argumentan estos autores, demuestra que los viajes en este internodo no solo involucraban grupos de tareas en busca de recursos (movilidad logística), sino familias enteras en tránsito hacia otros nodos para recolectar o intercambiar productos de oasis (p.e., frutos de algarrobo) en el marco de una movilidad de tipo residencial. En ocasiones, la resolución de este registro es tal, que permite adivinar eventos singulares y personajes individuales, como cuando la meteorización de los huesos lleva a concluir que ciertas personas viajaban solas y que pasó algún tiempo desde su muerte hasta que alguien las encontró y les dio sepultura. O como sucede en el análisis que Pimentel et al. hacen del caso de la mujer costera y el hombre caravanero con rastros de violencia y las posibles circunstancias en que fueron inhumados a fines del primer milenio d.C. en Calate 2.

El arte rupestre es otro registro potente para discutir personas, identidades e interacción social. Como es sabido, la propuesta que hiciera Núñez $(1976,1985)$ sobre la asociación entre arte rupestre y espacios de tránsito motivó un temprano interés en el estudio de las redes viales preincaicas en el sur andino y fue un punto de partida para la arqueología internodal. Los estudios realizados desde entonces han confirmado este vínculo, llevando además a discutir las relaciones entre ciertas expresiones de arte rupestre y prácticas o agentes internodales más allá de las rutas (p.e., Aschero 2000). Martel et al., por ejemplo, advierten que en Antofagasta de la Sierra los motivos de caravanas se encuentran plasmados fundamentalmente en las áreas densamente pobladas antes que en las rutas, lo que los lleva a plantear, alternativamente, su relación con viviendas de llameros locales (donde podrían ser parte de ceremonias de partida o arribo de tropas) o con viajeros de otros lares, temporalmente estacionados en dicho nodo para realizar sus cambalaches (cf. Valenzuela et al. 2011).

La relación entre arte rupestre y agenciamiento -recogiendo el concepto deleuziano que proponen Pimentel et al. - ha sido encarada de distintas formas. Una alternativa es tratar las imágenes como representaciones o vehículos de comunicación que transmiten información $y$ en tal sentido permiten, por ejemplo, identificar a sus realizadores (Núñez y Briones), reconstruir redes sociales (Gallardo et al. 2012) o demarcar intencionalmente el paisaje, contribuyendo así a la construcción de nichos ecológicos (Barberena et al.). Otra posibilidad es pensar que los interlocutores de esos gestos podrían ser también "personas no-humanas" ("other-than-human persons" (Hallowell 1960: 39)), que en otros regímenes ontológicos se consideran miembros plenos de la sociedad (Allen 2015; Descola 2013), lo que justificaría entender esos mensajes como gestos rituales (Nielsen et al. 2017). Otros irían más lejos, cuestionando el estatus ontológico de las propias imágenes -o del arte en general (Gell 1998)-, prefiriendo tratarlas como agentes por derecho propio, personas capaces de articular ellas mismas redes sociales en virtud de los efectos de su materialidad en la experiencia sensorial y en la práctica humana (Jones 2017). Esto 
no quiere decir que el arte rupestre siempre esté destinado a deidades o desempeñándose como persona, pero estas posibilidades deberían ser contempladas y evaluadas en función de los contextos. Tampoco excluye que las mismas imágenes operen simultáneamente en distintos campos y escalas temporales (dinámicas territoriales, procesos adaptativos, etc.), pero señala la importancia de considerar estos aspectos del "contexto de significación" (Aschero 1988) para entender los "sistemas de prácticas" (en el sentido realista, cf. Berenguer 1998) mediante los cuales dichos procesos y estructuras se hacían efectivas en cada caso. Bajo estas premisas, creo que el registro de ofrendas asociadas a geoglifos y grabados, así como a otros rasgos documentados a lo largo de las rutas circumpuneñas (apachetas, líneas de piedra, etc.) justifica plenamente que se les considere partícipes de ritos, como hacen aquí varios autores (Martel et al.; Núñez y Briones; Pimentel et al.).

La arqueología internodal ha demostrado la importancia que tienen para quienes se internan en estos espacios las negociaciones con las deidades a través de banquetes, pagos y otras rogativas, particularmente al encarar travesías largas o difíciles (Berenguer 2004; Briones et al. 2005; Núñez y Briones; Pimentel 2009). Lo mismo ha sido notado en las fuentes históricas y etnográficas sobre los viajes en los Andes (p.e., Albornoz 1967 [1584]; Lecoq 1987; Nielsen 1998-99). Cabe pensar que, con mayor o menor intensidad según el caso, estas prácticas se encuentran intrínsecamente vinculadas a la condición internodal, teniendo en cuenta que -por definición- este concepto remite a situaciones en que los individuos se encuentran lejos del amparo de su comunidad y de la sociedad humana en general. En estas circunstancias, no es sorprendente que busquen la asistencia de las personas no humanas que rigen su destino a través del rito (Nielsen et al. 2017).

El desierto interpuesto entre la costa y los oasis interiores de Atacama y Tarapacá aloja los testimonios más notables de estas prácticas. En el acotado segmento de Calate, Pimentel et al. reconocen tres tipos de estructuras ceremoniales, a saber, líneas de piedra, acumulaciones con oquedad central y camachicos. A ellos se suman algunos grabados y geoglifos. Estos últimos son ubicuos en la travesía de dos o tres jornadas que analizan Núñez y Briones entre Pica y la costa, concentrándose en pasos, encrucijadas y aguadas, y cobrando proporciones monu- mentales en las laderas de la cordillera de la Costa, donde ocasionalmente se asocian con sepulturas. Más al este, en las rutas que ascienden desde los oasis, comienza el dominio de la apacheta, una costumbre típicamente serrana que se extiende por todo el altiplano hasta el flanco oriental de los Andes. Entre los contextos de carácter ritual, sorprende la heterogeneidad de los materiales que fueron depositados en los camachicos, pequeños montículos que en la interpretación de Pimentel et al. reúnen referencias a diferentes regiones y "reinos". El conjunto depositado junto a un niño inhumado en un paradero de Calate a comienzos del primer milenio también incluye materiales de procedencia muy dispar, incluyendo una pipa del estilo San Francisco de los bosques del piedemonte trasandino. Otro tanto observan Núñez y Briones en los campamentos de Pintados, donde las ofrendas conjugan mariscos y pescados con maíces, pero también en los ajuares de los cementerios de la costa y del interior, que combinan materiales de ecozonas muy diferentes y alejadas entre sí. Estos registros señalan una vez más la importancia que asume en los rituales asociados al viaje, al tráfico y a sus protagonistas, la unión metafórica de los distintos lugares y seres que conforman el mundo.

Fuera de esta zona, los gestos rituales asociados a las travesías son menos visibles, pero también ubicuos. Hacia el sur del despoblado de Atacama, González et al. reportan en abras ofrendas de cuentas azules y desechos de su fabricación, objetos de metal -incluyendo un colgante de oro con iconografía formativa- conchas molidas, cerámica y otros objetos. Como es sabido, ch'allas similares, en las que predominan cuentas y fragmentos de rocas verdeazules y blancas (ceniza volcánica, concha) son ubicuas en los espacios de tránsito, cerros bajos, ojos de agua y otros puntos significativos del paisaje a ambos lados de los Andes sobre la transecta del trópico de Capricornio. Más al sur parece no haber este tipo de ofrendas. Al este de la cordillera, Martel et al. registran otra serie de rasgos posiblemente vinculados al rito en las rutas de la puna meridional, incluyendo mojones y numerosas acumulaciones de rocas de distintos tamaños, donde también se advierten juegos cromáticos, que en este caso contrastan cuarzos blancos con esquistos y vulcanitas grises oscuras. Durante la excavación de uno de estos montículos asociados a cerámicas del primer milenio pudieron establecer que su formación fue gradual, posiblemente mediante gestos similares a los que dan origen a las apachetas. 
Los patrones que surgen al comparar este registro en una escala espacial amplia permiten identificar ciertas situaciones internodales que típicamente requieren tratamiento ritual. Una consiste en uniones o encrucijadas de vías (palca) o puntos donde el terreno cambia abruptamente de pendiente (alca (Ricard Lanata 2007)). Otras podrían concebirse como portales o punkus (Cruz 2006), una categoría que incluiría pasajes estrechos y abras, quizás también vertientes, teniendo en cuenta que en los Andes se las considera a menudo como puertas a un mundo interior. Son contextos liminales, que requieren precaución y tal vez permisos de ciertas agencias que deben solicitarse mediante pagos. En otros casos, son recursos claves los que están siendo "marcados" con (o vigilados por) grabados, geoglifos, mojones, líneas de piedra o sepulturas. Estos gestos de apropiación comprenden recursos extractivos (como las andesitas trabajadas por caravaneros junto a geoglifos que reportan Blanco et al.) o que viabilizan el tránsito, como pastos, aguadas, alojamientos y ciertos tramos del propio camino. La posibilidad de que estas estructuras ceremoniales e imágenes estén actuando como personas (wak'as), y no solo como significantes, está sugerida por el hecho de que a veces reciben ellas mismas ofrendas.

También es interesante notar que las formas de relacionarse con agencias no humanas en estos contextos a veces refieren excluyentemente a ciertos colectivos, mientras que en otros casos vinculan a grupos diferentes en amplias "comunidades de práctica". La primera posibilidad comprende evidentemente los geoglifos que, como destacan Núñez y Briones, se distribuyen en áreas bien definidas y ostentan iconografías emblemáticas, integrando y demarcando territorios. Algo similar podría estar sucediendo con las líneas de piedra, que Pimentel et al. relacionan con los grupos costeros, quienes las posicionaron en relación a campamentos y puntos singulares de sus rutas. Distinto es el caso de las apachetas, las ofrendas de cuentas y rocas de colores, que tienen una amplia distribución circumpuneña -aun teniendo en cuenta la ausencia de apachetas en el desierto bajo- que no deja dudas sobre la participación de numerosas personas y diferentes grupos en estas rogativas. Los camachicos posiblemente correspondan a esta segunda categoría, teniendo en cuenta la existencia de rasgos similares muy perturbados -donde se observa una similar variedad de elementos- en abras de la reserva Eduardo Avaroa (Sud
Lípez) como Toro Muerto 2, Vallecito y Wajcha (Nielsen et al. 2017). Tal vez contextos semejantes se encuentren también más al este, donde podrían haber pasado inadvertidos hasta ahora por su baja visibilidad y la poca preservación de los materiales ofrendados. En todo caso, pareciera que estas obras de autoría colectiva y multiétnica expresen más sobre las agencias no humanas locales a quienes estuvieron destinadas que sobre la identidad de sus realizadores. Aun así, cabe pensar que estas obras contribuyen a reproducir, a su modo, sentidos suprarregionales de pertenencia que atraviesan las comunidades locales, más o menos territorializadas, tejiendo así una trama social más amplia. Serían colectivos integrados fundamentalmente a partir de agentes internodales, con códigos rituales compartidos pero con mínima copresencia, cuyo ensamblaje estaría mediado por estos rasgos y contextos ceremoniales, entre otros posibles. Berenguer y Salazar mencionan una idea afín al hablar de una "comunidad de semejantes", formada en las rutas y sitios de travesía a través de encuentros pasajeros entre personas con intereses y hábitos comunes.

El caso de la Puna argentina en tiempos coloniales presentado por Gil Montero et al. pone de manifiesto otras complejidades que asume la internodalidad cuando involucra la acción de formaciones estatales y se la estudia simultáneamente desde distintos registros. Tomando información de las visitas del siglo XVII, transponen el concepto de internodo a la espacialidad de las instituciones coloniales, donde se resignifica como vacíos de información, áreas donde la eficacia de los dispositivos de control del Estado es débil o nula, por ejemplo, para reclutar mano de obra, recoger tributo o extirpar idolatrías. Desde el imaginario y los valores hegemónicos, los internodos se convierten así en lugares lejanos, de extrema alteridad, donde viven criminales y ocurren cosas inmorales o extrañas. Así lo ilustra con elocuencia el testimonio que citan los autores sobre el amor entre dos hombres que convivían en Coranzulí, uno de los cuales "un mes es hombre y otro mes es mujer por providencias Divinas". Desde otro punto de vista, se trata de espacios de resistencia, donde surgen nuevos híbridos (como la chullpa-capilla de Licante (Rivet 2013) y se refugian grupos expertos en el "arte de no ser gobernados" (Scott 2008), como seguramente ocurrió con aquellos grupos calificados alternativamente como cimarrones o uros por Lozano Machuca (1992 [1581]: 31), que vivían "sin 
asiento ni lugar conocido" en algún lugar de Lípez y contaban con mucho ganado, pero se eximían de pagar tributo por tener fama de pobres.

\section{* Acuerdos y desacuerdos en territorio INTERNODAL}

Se desprende de lo dicho hasta aquí que las formas de apropiación y control que ejercen distintas comunidades sobre los espacios internodales es un tema central en este campo de investigación. ¿Qué prácticas y principios regulan el acceso a los recursos presentes allí y qué factores dan cuenta de sus variaciones? Barberena et al. proponen dos variables biogeográficas importantes al respecto, a saber, el grado de contraste en la distribución de recursos y la extensión de los internodos. Apelando a datos etnográficos generales, proponen un espectro de variabilidad que abarcaría tres situaciones; a saber, acceso restringido basado en la reciprocidad, acuerdos entre varios grupos para compartir recursos comunes y "tierras de nadie" potencialmente abiertas a todos. Modelos como éste son un punto de partida necesario para avanzar en la comprensión de las dinámicas territoriales internodales a través de su confrontación con diferentes casos. Los autores aplican su propuesta a los espacios internodales altos de la cordillera nor-patagónica, donde en las condiciones demográficas de ocupación efectiva propias del Holoceno Tardío esperan que se hayan establecido acuerdos de uso compartido o de acceso recíproco. Entienden que su expectativa se vería respaldada por la gran diversidad de motivos documentada en el arte rupestre internodal, que revelaría la convergencia de grupos diversos, aunque tal vez no de forma simultánea. Resulta interesante la posibilidad de poner a prueba estas ideas con otros casos contemporáneos, pero de mayor resolución temporal y conductual, ya que podría ayudar a identificar variables relevantes que se desdibujan en el registro acumulado de la larga duración, a entender las jerarquías causales que mencionan los autores y el lugar que cabe a distintas herramientas teóricas.

El desierto de Atacama, por ejemplo, es un espacio internodal muy extenso, de ínfima productividad y alto contraste con sus potenciales nodos, tanto interiores como litorales. Los trabajos de este volumen plantean diferentes situaciones en relación a recursos valorados en este escenario biogeográfico. Rocas relativamente abun- dantes, como sílice o andesita, parecen estar disponibles para cualquiera que llegue hasta donde se encuentran; mientras que las más raras y concentradas son de acceso restringido, como sucede en Las Turquesas, donde la extracción pasa de las manos de grupos atacameños a portadores de cerámica Ánimas durante el Período Medio, pero vuelve a control atacameño en el Intermedio Tardío (González et al.). Por su parte, Núñez y Briones interpretan a Mocha como un enclave donde tarapaqueños y altiplánicos se encontraban en términos pacíficos a explotar bienes distintos valorados por cada uno, minerales de cobre y maíz, respectivamente, aunque la presencia de lo que podrían ser rasgos defensivos en el lugar sugiere la posibilidad de que este acuerdo recíproco haya estado cerrado a otros grupos.

Pero los recursos más valiosos y disputados en un escenario biogeográfico como éste eran, indudablemente, los que permitían el tránsito y, por lo tanto, la circulación de bienes complementarios que eran vitales para todos. Núñez y Briones argumentan contundentemente en favor de la territorialización de estas rutas a través de geoglifos emblemáticos y todo tipo de dispositivos rituales vigilando vías, paraderos, aguadas y parches de pastura, control que era aparentemente permeable a los grupos costeros, quienes abrirían recíprocamente sus lugares a colonos del interior, pero que ciertamente estaban cerrados a otras "concertaciones territoriales" similares, como la que pudo existir más al sur entre costeros y atacameños. Es sobre esta frontera donde se concentran los indicios de conflicto, como en el "embudo vial intercultural" de Calate, donde Pimentel et al. reportan rastros de violencia en los cuerpos y sus contextos, alusiones explícitas en los geoglifos a la hostilidad que en ciertas épocas pudo existir entre viajeros de distinta procedencia y hasta hallazgos de cabezales líticos con fracturas de impacto. Cabe destacar en este sitio la inhumación en el Intermedio Tardío de un caravanero adulto acompañado -entre otros objetos- por tres túnicas, dos de estilo tarapaqueño y una atacameña. Este registro pone de relieve la presencia de agentes internodales capaces de atravesar regularmente fronteras conflictivas merced a su capacidad de manipular elementos diacríticos y encuentra eco directo en la mentada cita de Lozano Machuca sobre esos

...otros indios que confinan con los indios de guerra de Omaguaca y Casabindo y tienen trato y comercio con 
estos Lipes, los cuales están neutrales, que no son de paz ni de guerra, y entran en Potosí con nombre de indios Lipez y Atacamas, con ganados y otras cosas de venta y rescate (Lozano Machuca 1992 [1581]: 31, énfasis agregado).

En suma, se trata de un vasto espacio internodal saturado de imágenes y ritos dispares, algunos de carácter diacrítico, otros no, atravesado por grupos de diferente procedencia e identidad, que disputan o comparten recursos distintos bajo acuerdos y mecanismos variables. Difícilmente podría "desempaquetarse" semejante complejidad a partir de un registro promediado con poca preservación y visibilidad, pero el ejercicio, además de ayudar a pensar hipótesis más precisas, permite señalar algunos recaudos generales que podrían ser útiles para avanzar en esa dirección. Uno de ellos es analizar separadamente las condiciones de negociación de distintos recursos potencialmente valorados en el espacio internodal, considerando que podrían estar sometidos a acuerdos diferentes, incluso entre los mismos grupos. Otro es recordar que el valor del tránsito internodal para los distintos actores involucrados no se relaciona con recursos presentes allí, sino en los nodos circundantes o más allá, lo que requiere tomar en consideración contextos mayores. Tercero es considerar procesos de integración política que afectarían la capacidad y formas de negociar acuerdos de distintos agentes o colectivos; ejemplo de esto serían las aparentes asimetrías entre las fragmentarias comunidades costeras y una federación étnica como Pica/Tarapacá, con capacidad para actuar consistentemente sobre un vasto territorio e incluso destinar autoridades a zonas potencialmente conflictivas como las que identifican Núñez y Briones en distintos cementerios.

\section{* Conclusión: CAMinos POR Recorrer}

La arqueología internodal ha sido un campo de investigación muy prolífico, teniendo en cuenta su relativamente corta vida. Como lo ilustran los trabajos comentados, ha contribuido con datos importantes para llevar la discusión sobre los procesos de interacción interregional en los Andes a un nivel de resolución muy diferente al que tenía décadas atrás, cuando se hablaba vagamente de "fajas de interacción" o "sistemas de complementariedad", casi exclusivamente sobre la base de datos funerarios o domésticos nodales y analogías generales de tipo histórico o etnográfico. Pero también ha desarrollado conceptos y modelos fértiles, que permiten trabajar este peculiar registro de formas novedosas y articularlo con diversas líneas de evidencia de los nodos. Esto justifica tratarlo actualmente como un programa de investigación con premisas, métodos y objetivos propios.

Así entendido, creo que su principal desafío hoy es salir del "laboratorio del desierto" y tierras altas aledañas donde fue criado. Esto implica, ante todo, trasladarlo a otras geografías. Como lo sugiere la antigua metáfora caravanera, según la cual los camellos serían los navíos del desierto, existen buenas posibilidades de sinergia con la arqueología de paisajes marítimos e insulares, que trabajan con extensos espacios internodales atravesados por "camellos del mar". Más difícil será aplicarlo a zonas con menores contrastes en la distribución de recursos, como ya hacen algunos autores en esta compilación. Regiones con ofertas de nutrientes más uniformes, por ejemplo, podrían ayudar a reconocer más nítidamente la contribución que hace la memoria social -con su característico arraigo a los lugares- en la localización persistente de ciertos nodos y, por lo tanto, de sus intersticios. Ciertos ambientes también condicionan de modo diferente la formación y visibilidad del registro arqueológico internodal. ¿Cómo encarar este tipo de estudios en terrenos selváticos o de monte, donde la vegetación rápidamente absorbe las vías y los escenarios que no son permanentemente ocupados?

Otra posibilidad es estrechar el diálogo con campos temáticos ya desarrollados en la investigación arqueológica. Blanco et al. señalan acertadamente que la arqueología de la minería tiene mucho que ofrecer para entender ciertas actividades y lugares comúnmente presentes en áreas internodales. Ya se han hecho ensayos para trabajar con conceptos y modelos formulados originalmente en la arqueología de cazadores-recolectores, pero es necesario profundizar el intercambio. Estos contextos son particularmente relevantes para nosotros, teniendo en cuenta que las bajas densidades demográficas en que suelen actuar dichos grupos resultan en paisajes con extensas áreas solo ocupadas en contextos de movimiento o escasamente aprovechadas, al menos en escalas temporales cortas.

Más aventurada aún es la apuesta que hacen Gil Montero et al. cuando ponen en juego las fuentes históricas para cotejarlas con el registro arqueológico. Esto los lleva a 
trasponer el concepto de internodo a otro tipo de espacialidad, la de las instituciones coloniales hispanas y, en general, la de los dispositivos de control de la población que típicamente implementan los Estados. Desde allí se divisan otros horizontes más alejados todavía, vinculados a la espacialidad virtual de las representaciones (Foucault y Miskowiec 1986), de imaginarios como el de aquellos funcionarios coloniales que contemplaban con horror una puna de Atacama poblada de bandidos y transves- tidos. Para avanzar en esos internodos convendría explorar otros recursos cartográficos, más apropiados para captar la topología de tales geografías, como han sugerido colegas etnólogos en relación a las concepciones del espacio en los Andes (Platt et al. 2006: 19).

Los destinos de estas vías de investigación no han sido establecidos todavía, habrá que recorrerlas. Por ahora, sus límites dependen fundamentalmente de nuestra imaginación.

\section{* Referencias citadas}

ALBECK, M.E. 1994. De costa a selva. Producción e intercambio entre los pueblos agroalfareros de los Andes Centro Sur. Instituto Interdisciplinario Tilcara, Tilcara.

ALBORNOZ, C. de. 1967 [1584]. Instrucción para descubrir todas las guacas del Pirú y sus camayos y haziendas. Journal de la Société des Américanistes LVI(I): 17-29.

ALLEN, C. 2015. The whole world is watching: new perspectives on Andean animism. In The Archaeology of Wak'as: Explorations of the Sacred in the Pre-Columbian Andes. T. Bray (Ed.), pp. 23-46. University Press of Colorado, Boulder.

ASCHERO, C. 1988. Pinturas rupestres, actividades y recursos naturales: un encuadre arqueológico. En Arqueología contemporánea argentina. Actualidad y Perspectivas, pp. 109-145. Ediciones Búsqueda, Buenos Aires.

ASCHERO, C. 2000. Figuras humanas, camélidos y espacios en la interacción circumpuneña. En Arte en las rocas. Arte rupestre, menhires y piedras de colores en Argentina. M. Podestá y M. de Hoyos (Eds.), pp. 15-44. Sociedad Argentina de Antropología y Asociación de Amigos INAPL, Buenos Aires.

BERENGUER, J. 1998. La iconografía del poder en Tiwanaku y su rol en la integración de zonas de frontera. Boletín del Museo Chileno de Arte Precolombino 7: 19-37.

BERENGUER, J. 2004. Tráfico de caravanas, interacción interregionaly cambio cultural en la Prehistoria Tardía del Desierto de Atacama. Ediciones Sirawi, Santiago de Chile.

BERENGUER, J. y G. PIMENTEL. 2010. Presentación del simposio "Arqueología de los espacios vacíos: una aproximación internodal a las relaciones societales". En Actas del XVII Congreso Nacional de Arqueología Chilena, t. 2, pp. 1305-1308. Universidad Austral de Chile, Valdivia.
BERENGUER, J., I. CÁCERES, C. SANHUEZA y P. HERNÁNDEZ. 2005. El Qhapaqñan en el Alto Loa, Norte de Chile: Un estudio micro y macromorfológico. Estudios Atacameños 29: 7-39.

BORGATTI, S.P., A. MEHRA, D.J. BRASS y G. LABIANCA. 2009. Network analysis in the social sciences. Science 323 (April): 892-896.

BORRerO, L.A. 1994-1995. Arqueología de la Patagonia. Palimpsesto. Revista de Arqueología 4: 9-69.

BORRERO, L.A. 2015. Moving: hunter-gatherers and the cultural geography of South America. Quaternary International 363: $126-$ 133.

BOUYSSE-CASSAGNE, T. y O. HARRIS. 1987. Pacha: en torno al pensamiento aymara. Tres Reflexiones sobre el Pensamiento Andino, pp. 11-59. Hisbol, La Paz.

BOWMAN, I. 1924. Desert Trails of Atacama. American Geographical Society, Special Publication 5. New York.

BRIONES, L., L. NÚÑEZ y V. STANDEN. 2005. Geoglifos y tráfico prehispánico de caravanas de llamas en el desierto de Atacama (Norte de Chile). Chungara. Revista de Antropología Chilena 37: 195-223.

BRUGHMANS, T. 2013. Thinking through networks: a review of formal network methods in archaeology. Journal of Archaeological Method and Theory 20: 623-662.

CASES, B., C. REES, G. PIMENTEL, R. LABARCA y D. LEIVA. 2008. Sugerencias desde un contexto funerario en un "espacio vacío" del desierto de Atacama. Boletín del Museo Chileno de Arte Precolombino 13: 51-70.

CHERTUDI, S. y S. NEWBERY, 1966-1967. La Difunta Correa. Cuadernos del Instituto Nacional de Antropología 6: 95-178. 
COLLAR, A., F. COWARD, T. BRUGHMANS y B. MILLS. 2015. Networks in archaeology: phenomena, abstraction, representation. Journal of Archaeological Method and Theory 22: 1-32.

CRUZ, P. 2006. Espacios permeables y espacios peligrosos. Consideraciones acerca de punkus y qaqas en el paisaje altoandino de Potosí, Bolivia. Boletín del Museo Chileno de Arte Precolombino 11(2): 35-50.

CURTONI, R.P. 2007. Análisis e interpretación de las rastrilladas indígenas del sector centro-este de la provincia de La Pampa. Revista de Arqueología Histórica Argentina y Latinoamericana 1: 65-92.

DESCOLA, P. 2013. Beyond nature and culture. University of Chicago Press, Chicago.

FOUCAULT, M. y J. MISKOWIEC. 1986. Of other spaces. Diacritics 16(1): 22-27.

GALLARDO, F. y G. CABELLO. 2015. Emblems, Leadership, Social Interaction and Early Social Complexity: The Ancient Formative Period (1500 BC-AD 100) in the Desert of Northern Chile. Cambridge Archaeological Journal 25: 615-634.

GALlARDO, F., G. CABELlO, G. PIMENTEL, M. SEPÚlVEDA y L. CORNEJO. 2012. Flujos de información visual, interacción social y pinturas rupestres en el desierto de Atacama (norte de Chile). Estudios Atacameños. Arqueología y Antropología Surandinas 43: 35-52.

GELL, A. 1998. Art and Agency. Clarendon Press, Oxford.

GIL MONTERO, R. 2011. Los pastores frente a la minería colonial temprana: Lípez en el siglo XVII. En En ruta. Arqueología, historiay etnografía del tráfico sur andino, L. Núñez y A.E. Nielsen (Eds.), pp. 285-312. Encuentro Grupo Editor, Córdoba.

GJESFJELD, E. 2015. Network Analysis of archaeological data from Hunter-Gatherers: methodological problems and potential solutions. Journal of Archaeological Method and Theory 22: 182-205.

GOÑI, R. 1987. Arqueología de sitios tardíos en el Valle del Río Malleo, Provincia de Neuquén. Relaciones de la Sociedad Argentina de Antropología XVII: 37-66.

HALLOWELL, A. 1960. Ojibwa ontology, behavior, and world view. En Culture in history: essays in honor of Paul Radin, S. Diamond (Ed.), pp. 19-52. Columbia University, New York.

HELMS, M.W. 1988. Ulysses' Sail: An Ethnographic Odyssey of Knowledge, Power, and Geographical Distance. Princeton University Press, Princeton.
HODDER, I. 2012. Entangled: an archaeology of the relationships between humans and things. Wiley Blackwell, Oxford.

HODDER, I. yA. MOL. 2016. Network analysis and entanglement. Journal of Archaeological Method and Theory 23: 1066-1094.

INGOLD, T. 1993. The temporality of the landscape. World Archaeo$\log 25: 152-174$.

INGOLD, T. 2011. Being alive. Essays on movement, knowledge and description. Routledge, London.

JONES, A. 2017. Rock art and ontology. Annual Review of Anthropo$\log 46: 167-181$.

KNAPPETT, C. 2011. An archaeology of interaction: network perspectives on material culture and society. Oxford University Press, Oxford.

LATOUR, B. 2005. Reassembling the social: An introduction to actornetwork-theory. Oxford University Press, Oxford.

LAZZARI, M. 2016. Stones to build a world: circulation and value of materials in Pre-Columbian Northwestern Argentina. Cambridge Archaeological Journal 26: 1-22.

LECHTMAN, H. (Ed.). 2006. Esferas de interacción prehistóricas y fronteras nacionales modernas: los Andes Sur Centrales. Instituto de Estudios Peruanos - Institute of Andean Research, Lima.

LECOQ, P. 1987. Caravanes de lamas, sel et échanges dans une communauté de Potosí, en Bolivie. Bulletin de l'Institut Français d'Etudes Andines XVI, núm. 3-4: 1-38.

LOZANO MACHUCA, J. 1992 [1581]. 'Carta del Factor de Potosí... al Virrey del Perú, en donde se describe la Provincia de los Lípez'. Estudios Atacameños 11: 30-34.

MARTEL, A. 2014. Aguas Calientes. Evidencias directas del tráfico caravanero entre la Puna meridional y el valle Calchaquí. Estudios Sociales del NOA 13: 103-124.

MARTÍNEZ, J.L. 1998. Pueblos del chañar y el algarrobo: Los atacamas en el siglo XVII. Dibam, Santiago.

MILLS, B.J., M.A. PEEPLES, W.R. HAAS, L. BORCK, J.J. CLARK y J.M. ROBERTS. 2015. Multiscalar perspectives on social networks in the late Prehispanic Southwest. American Antiquity 80 : 3-24.

NIELSEN, A.E. 1997. El Tráfico Caravanero Visto desde la Jara. Estudios Atacameños 14:339-371. 
NIELSEN, A.E. 1998-1999. Tráfico de caravanas en el sur de Bolivia: observaciones etnográficas e implicancias arqueológicas. Relaciones de la Sociedad Argentina de Antropología 22/23: 139-178.

NIELSEN, A.E. 2001. Evolución social en Quebrada de Humahuaca (AD 700-1536). En Historia argentina prehispánica, E. Berberián y A. Nielsen (Eds.), vol. I: 171-264. Editorial Brujas, Córdoba.

NIELSEN, A.E. 2006. Estudios internodales e interacción interregional en los Andes Circumpuneños: teoría, método y ejemplos de aplicación. En Esferas de interacción prehistóricas y fronteras nacionales modernas: los Andes Sur Centrales, H. Lechtman (Ed.), pp. 29-62. Instituto de Estudios Peruanos - Institute of Andean Research, Lima.

NIELSEN, A.E. 2007. Bajo el hechizo de los emblemas: políticas corporativas y tráfico interregional en los Andes Circumpuneños. En Producción y Circulación Prehispánicas de Bienes en el Sur Andino, A. Nielsen, M. C. Rivolta, V. Seldes, M. Vázquez y P. Mercolli (Comps.), pp. 393-411. Editorial Brujas, Córdoba.

NIELSEN, A.E. 2013. Circulating objects and the constitution of South Andean society (500 BC-AD 1550). En Merchants, trade, and exchange in the Pre-Columbian World, K. Hirth y J. Pillsbury (Eds.), pp.389-418. Dumbarton Oaks, Washington D.C.

NIELSEN, A.E., P.H. MERCOLLI y N. NASIF. 2010. Ocupaciones temporarias y explotación faunística en la Región Lacustre Altoandina. En Actas del ХVI Congreso Nacional de Arqueología Chilena, vol. 2: 1365-1378. Valdivia.

NIELSEN, A.E., C.I. ANGIORAMAy F. ÁVILA, 2017. Ritual as interaction with non-humans: Pre-Hispanic mountain pass shrines in the Southern Andes. En Rituals of the past. Prehispanic and Colonial case studies in Andean archaeology, S. Rosenfeld y S. Bautista (Eds.), pp. 241-266. University Press of Colorado, Boulder.

NIELSEN, A.E., C.I. ANGIORAMA, J. MARYAÑSKI, F. ÁVILA y M.L. LÓPEZ. 2015. Paisajes prehispánicos Tardíos en San Juan Mayo (frontera Argentina-Bolivia). Arqueología 21 dossier: 29-61.

NIELSEN, A.E.; M.M. VÁZQUEZ; J.C. AVALOS y C.I. ANGIORAMA. 1999. Prospecciones Arqueológicas en la Reserva "Eduardo Avaroa" (Sud Lípez, Depto. Potosí, Rep. de Bolivia). Relaciones de la Sociedad Argentina de Antropología XXIV: 95-124.

NÚÑEZ, L. 1976. Geoglifos y tráfico de caravanas en el desierto chileno. En Volumen de Homenaje al R. P. Gustavo Le Paige, pp. 148202. Universidad del Norte, Antofagasta.

NÚÑEZ, L. 1985. Petroglifos y tráfico de caravanas en el desierto chileno. En Estudios en arte rupestre, C. Aldunate, J. Berenguer y V. Castro (Eds.), pp. 243-264. Museo Chileno de Arte Precolombino, Santiago.
NÚÑEZ, L. 1999. Valoración minero-metalúrgica circumpuneña: menas y mineros para el Inka rey. Estudios Atacameños 18: 177-221.

NÚÑEZ, L. y T. DILLEHAY. 1979. Movilidad giratoria, armonía social y desarrollo en los Andes meridionales: patrones de tráfico e interacción económica (ensayo). Universidad del Norte, Antofagasta.

NÚÑEZ, L., M. GROSJEAN e I. CARTAJENA. 2005. Ocupaciones humanas y paleoambientes en la Puna de Atacama. Universidad Católica del Norte-Taraxacum, Antofagasta.

NÚÑEZ, L. y A. NIELSEN (Eds). 2011. En ruta. Arqueología, historia y etnografía del tráfico sur andino. Encuentro Grupo Editor, Córdoba.

PALERMO, M.A. 2000. A través de la frontera. Economía y sociedad indígenas desde el tiempo colonial hasta el siglo XIX. Nueva Historia Argentina 1, pp. 343-382.

PESTLE, W., C. TORRES-ROUFF, M. HUBBE, F. SANTANA, G. PIMENTEL, F. GALLARDO y K.J. KNUDSON. 2015. Explorando la diversidad dietética en la prehistoria del desierto de Atacama: un acercamiento a los patrones regionales. Chungara. Revista de Antropología Chilena 47: 201-209.

PIMENTEL, G. 2009. Las huacas del tráfico. Arquitectura ceremonial en rutas prehispánicas del Desierto de Atacama. Boletín del Museo Chileno de Arte Precolombino 14: 9-38.

PIMENTEL, G., C. REES, P. DE SOUZA y L. ARANCIBIA. 2011. Viajeros costeros y caravaneros. Dos estrategias de movilidad en el Período Formativo del Desierto de Atacama, Chile. En En ruta. Arqueología, historia y etnografía del tráfico sur andino, L. Núñez y A. E. Nielsen (Eds.), pp. 43-81. Encuentro Grupo Editor, Córdoba.

PLATT, T., T. BOUYSSE-CASSAGNE y O. HARRIS. 2006. Qaraqara-Charka: Mallku, Inka y Rey en la Provincia de Charcas. Historia Antropológica de una Confederación Aymara. Instituto Francés de Estudios Andinos, La Paz.

RENFREW, C. 1975. Trade as action at a distance: questions of integration and communication. En Ancient Civilization and Trade, J. Sabloff y C. Lamberg-Karlovsky (Eds.), pp. 3-59. University of New Mexico Press, Albuquerque.

RICARD LANATA, X. 2007. Ladrones de Sombra: El Universo Religioso de los Pastores del Ausangate. IFEA - Centro Bartolomé de Las Casas, Lima.

RIVET, M.C. 2013b. Cruces e iglesias en un contexto chullpario: Arte rupestre colonial en las tierras altas atacameñas. Nuevo Mundo Mundos Nuevos [en línea] Debates, Puesto en línea el 14.02 .2013 . 
SALAZAR, D. 2008. La producción minera en San José del Abra durante el período Tardío atacameño. Estudios atacameños. Revista de Arqueología y Antropología Surandinas 36: 43-72.

SANHUEZA, C. 2011. Atacama y Lípez. Breve historia de una ruta: escenarios históricos, estrategias indígenas y ritualidad andina. En En ruta. Arqueología, historia y etnografía del tráfico sur andino, L. Núñez y A. E. Nielsen (Eds.), pp. 313-339. Encuentro Grupo Editor, Córdoba.

SCOTT, J.C. 2008. The Art of not Being Governed: An Anarchist History of Upland Southeast Asia. Yale University Press, New Haven.

SMITH, M.L. 2007. Territories, corridors, and networks: a biological model for the premodern state. Complexity 12(4): 28-35.

SOJA, E.W. 1989. Postmodern geographies: the reassertion of space in critical social theory. Verso Press, London.

TORRES-ROUFF, C., G. PIMENTELy M. UGARTE. 2012. ¿Quiénes viajaban? Investigando la muerte de viajeros post arcaicos en el Desierto de Atacama (ca. 800 AC-1536 DC). Estudios Atacameños. Revista de Arqueología y Antropología Surandinas 43: 167-186.

TROMBOLD, C., 1991. An introduction to the study of ancient New World road networks. In Ancient Road Networks and Settlement Hierarchies in the New World, C. Trombold (Ed.), pp. 1-9. Cambridge University Press, Cambridge.
VALENZUELA, D., C. SANTORO y L. BRIONES. 2011. Arte rupestre, tráfico e interacción social: cuatro modalidades en el ámbito exorreico de los Valles Occidentales, Norte de Chile (Períodos Intermedio Tardío y Tardío, ca. 1000-1535 d.C.). En En ruta. Arqueología, historia y etnografía del tráfico sur andino, L. Núñez y A. E. Nielsen (Eds.), pp. 199-245. Encuentro Grupo Editor, Córdoba.

WEST, T. 1981. Sufriendo Nos Vamos: From a Subsistence to a Market Economy in an Aymara Community of Bolivia. Tesis doctoral, New School for Social Research. University Microfilms International, Ann Arbor.

WHALLON, R. 2006. Social networks and information: Non"utilitarian" mobility among hunter-gatherers. Journal of Anthropological Archaeology 25: 259-270.

YACOBACCIO, H.D., 1994. Biomasa animal y consumo en el Pleistoceno-Holoceno Surandino. Arqueología 4: 43-71.

YACOBACCIO, H.D., 2013. Towards a human ecology for the Middle Holocene in the Southern Puna. Quaternary international 307: 24-30. 
